\title{
Effective temperature management
}

\author{
Ian Tweedie \\ From Targeted Temperature Management (TTM 2014) \\ Berlin, Germany. 6-7 November 2014
}

'It is not enough just to influence body temperature - you have to control it' (M Holzer, Therapeutic Temperature Management (TTM) 2012, Berlin). For this to be possible we need the ideal cooling equipment/technique and a reliable temperature monitoring technique. Many techniques are available [1], but only two types meet most of the ideal characteristics - automatic temperature feedbackcontrolled surface hydrogel pads or endovascular cooling devices.

To be fully effective, control is needed for all three phases of TTM.

Induction - the how and when are to an extent disease dependent. The evidence is mainly animal based [2] and the human evidence can be conflicting [3], although the suggestion appears to be the sooner the better. Decision to target temperature times are similar for both types of devices, but may be enhanced with the use of adjuncts, such as intravenous infusion of cold fluids. Surface cooling is negatively influenced by obesity and pyrexia, with $32 \%$ of patients failing to reach the target in $<12$ hours [4].

Maintenance - how deep and how long? Some guidance does exist for depth on a disease process basis (for example, 2010 European resuscitation guidelines). Most evidence is available for post-cardiac arrest, cooling to $<34^{\circ} \mathrm{C}$. However, recent evidence suggests that preventing fever by cooling to $36^{\circ} \mathrm{C}$ is just as effective as cooling to $33^{\circ} \mathrm{C}$ [5]. Duration appears to correlate with outcome. Animal studies support this [2] and human studies are suggestive. For TBI, mortality is definitely better but neurologic outcome is less clear [6]. Although each technique has its own advantages, overall both seem equally effective at maintaining a stable target temperature [7]. However, for it to be successful, complications of TTM need to be effectively managed.

Rewarming - often the Cinderella, but it has been long known that it can affect the neurological outcome. The question that has as yet to be answered is how fast?

\footnotetext{
Department of Neuroanaesthesia and Critical Care, The Walton Centre NHS
} $\mathrm{FT}$, Liverpool, UK

The consensus based on evidence available is that slow is best for the brain for both mortality and neurological outcome [6], whilst avoiding post-rewarming fever. Both types of device seem to be able to control rewarming adequately.

So how can you choose which device to use, as each seems to be effective in all three phases? Long-term use of endovascular devices for fever control is associated with a higher incidence of VTE and PE [8]. Thus, for longer term temperature management the surface device may be the more appropriate

In conclusion, effective temperature control is essential for TTM, this is best achieved with temperature feedback control devices, and management of complications is an essential part of the care. Is fever control the new goal for post-cardiac arrest and ischaemic stroke?

\section{Financial disclosure}

IT has received an honorarium and travel costs from C. R. BARD.

\section{Declaration}

This abstract and supplement was proposed, developed and commissioned by BMC Emergency Medicine and was funded by an educational grant from C. R. BARD, NJ, USA. The published abstract was independently prepared by the author. C. R. BARD had no input into the content.

\section{Published: 24 June 2015}

\section{References}

1. Polderman $\mathrm{K}$, Herold I: Therapeutic hypothermia and controlled normothermia in the intensive care unit: practical considerations, side effects, and cooling methods. Crit Care Med 2009, 37:1101-20.

2. Che D, Luchuan L, Kopil C, et al: Impact of therapeutic hypothermia onset and duration on survival, neurologic function, and neurodegeneration after cardiac arrest. Crit Care Med 2011, 39:1426-30.

3. Nielsen N, Hovdenes J, Nilsson F, et al: Outcome, timing and adverse events in therapeutic hypothermia after out-of-hospital cardiac arrest. Acta Anaesthesiol Scand 2009, 53:926-34.

4. Ricome S, Dumas F, Mongardon N, et al: Predictors of external cooling failure after cardiac arrest. Intensive Care Med 2013, 39:620-8.

5. Nielsen N, Wetterslev J, Cronberg T, Erlinge D, Gasche Y, Hassager C, et al: Targeted temperature management at 33 degrees $C$ versus 36 degrees C after cardiac arrest. N Engl J Med 2013, 369:2197-206. 
6. Mclntyre L, Ferguson D, Hébert $P$, et al: Prolonged therapeutic hypothermia after traumatic brain injury in adults - a systematic review. JAMA 2003, 289:2992-9.

7. Tømte $\varnothing$, Drægni T, Mangschau A, et al: A comparison of intravascular and surface cooling techniques in comatose cardiac arrest survivors. Crit Care Med 2011, 39:443-9.

8. Mũller A, Lorenz A, Seifert B, Keller E: Risk of thromboembolic events with endovascular cooling catheters in patients with subarachnoid hemorrhage. Neurocrit Care 2014, 21:207-10.

doi:10.1186/1471-227X-15-S1-A13

Cite this article as: Tweedie: Effective temperature management. BMC Emergency Medicine 2015 15(Suppl 1):A13.

Submit your next manuscript to BioMed Central and take full advantage of:

- Convenient online submission

- Thorough peer review

- No space constraints or color figure charges

- Immediate publication on acceptance

- Inclusion in PubMed, CAS, Scopus and Google Scholar

- Research which is freely available for redistribution

Submit your manuscript at www.biomedcentral.com/submit 